\title{
Avaliação dos cardápios quanto a composição nutricional de escolas municipais da área urbana e rural da cidade de Manaus
}

\author{
Evaluation of menus regarding the nutritional composition of municipal schools in the urban and \\ rural areas of the city of Manaus
}

Evaluación de menús sobre la composición nutricional de las escuelas municipales del área urbana y rural de la ciudad de Manaus

\author{
Andrezza Martins dos Santos \\ ORCID: https://orcid.org/0000-0003-1380-1192 \\ Centro Universitário Fametro, Brasil \\ E-mail: andrezza1993ciagdhan @gmail.com \\ Elves Fadoul da Costa \\ ORCID: https://orcid.org/0000-0001-6951-5174 \\ Centro Universitário Fametro, Brasil \\ E-mail: fadulbrasil@gmail.com \\ José Carlos de Sales Ferreira \\ ORCID: https://orcid.org/0000-0002-1867-8229 \\ Centro Universitário Fametro, Brasil \\ E-mail: jcarlos.sales@gmail.com
}

\begin{abstract}
Resumo
Introdução: a alimentação escolar é importante para que todas as crianças estejam bem alimentadas evitando desatenção durante as aulas ou baixo rendimento no período escolar. E para que isso ocorra, o Programa Nacional de Alimentação Escolar (PNAE) deve funcionar corretamente na elaboração dos cardápios com base nas próprias diretrizes. Objetivos: Avaliar os cardápios quanto a composição nutricional das Escolas Municipais, área urbana e rural, da cidade de Manaus com base nos critérios estabelecidos na elaboração de cardápios do PNAE. Materiais e Métodos: É uma pesquisa do tipo descritivo, qualitativa e quantitativa, com avaliação documental dos cardápios de 2019 das Escolas Municipais do Ensino Fundamental I, disponibilizados no site oficial da Secretaria Municipal de Educação (Semed). Resultados: os teores médios de energia dos cardápios resultaram em 408,47 Kcal, distribuídos em 17,07g de proteínas, 10,09g de lipídios, 63,27g de carboidratos e 5,53 g de fibras. Observou-se que os valores da quantidade de energia, macronutrientes e fibras são preocupantes, pois estão acima dos valores de referência. Já o cálcio é de $157,85 \mathrm{mg}$ e o ferro é 2,61 mg, ou seja, o cálcio está dentro da recomendação enquanto o ferro se encontra acima do valor de referência. Conclusão: é necessário realizar mudanças no cardápio para que as crianças possam obter as necessidades nutricionais adequadas e assim tornar o rendimento escolar delas mais produtivo, já que as necessidades nutricionais diárias de macronutrientes, quantidade de calorias, fibras e ferro oferecidos nos cardápios estavam acima da recomendação. Além de priorizar por alimentos regionais nos cardápios.
\end{abstract}

Palavras-chave: Composição nutricional; Cardápios; PNAE, Alimentação escolar; Escolas públicas.

\begin{abstract}
Introduction: school meals are important so that all children are well-fed, avoiding inattention during classes or low performance during the school period. And for that to happen, the National School Feeding Program (PNAE) must work correctly in the elaboration of the menus based on the guidelines themselves. Objectives: To evaluate the menus regarding the nutritional composition of Municipal Schools, urban and rural areas of the city of Manaus, based on the criteria developed in the preparation of PNAE menus. Materials and Methods: It is a descriptive, qualitative and quantitative research, with documentary evaluation of the 2019 menus of the Municipal Schools of Elementary Education I, available on the official website of the Municipal Department of Education (Semed). Results: The average energy content of the menus resulted in $408.47 \mathrm{Kcal}$, distributed in $17.07 \mathrm{~g}$ of proteins, $10.09 \mathrm{~g}$ of lipids, $63.27 \mathrm{~g}$ of carbohydrates and $5.53 \mathrm{~g}$ of fibers. Note that the values for the amount of energy, macronutrients and fibers are of concern, as they are above the reference values. Calcium is $157.85 \mathrm{mg}$ and iron is $2.61 \mathrm{mg}$, that is, calcium is within the recommendation while iron is above the reference value. Conclusion: It is necessary to make changes to the menu so that children can obtain the nutritional needs indicated and thus make their school performance more productive, since the daily nutritional needs for macronutrients, the amount of calories, fibers and iron offered in the menus were above of the recommendation. In addition to prioritizing regional foods on the menus.
\end{abstract}

Keywords: Nutritional composition; Menus; PNAE; School alimentation; Public schools. 


\begin{abstract}
Resumen
Introducción: Las comidas escolares son importantes para que todos los niños estén bien alimentados, evitando la falta de atención durante las clases o el bajo rendimiento durante el período escolar. Y para que eso suceda, el Programa Nacional de Alimentación Escolar (PNAE) debe funcionar correctamente en la elaboración de los menús en base a las propias pautas. Objetivos: Evaluar los menús en cuanto a la composición nutricional de Escuelas Municipales, áreas urbanas y rurales de la ciudad de Manaus, en base a los criterios desarrollados en la elaboración de los menús del PNAE. Materiales y Métodos: Se trata de una investigación descriptiva, cualitativa y cuantitativa, con evaluación documental de los menús 2019 de las Escuelas Municipales de Educación Primaria I, disponible en el sitio web oficial de la Secretaría Municipal de Educación (Semed). Resultados: El contenido energético medio de los menús resultó en 408,47 Kcal, distribuidas en 17,07 g de proteínas, 10,09 g de lípidos, 63,27 g de carbohidratos y 5,53 g de fibras. Tenga en cuenta que los valores para la cantidad de energía, macronutrientes y fibras son preocupantes, ya que están por encima de los valores de referencia. El calcio es $157,85 \mathrm{mg}$ y el hierro 2,61 mg, es decir, el calcio está dentro de la recomendación mientras que el hierro está por encima del valor de referencia. Conclusión: Es necesario realizar cambios en el menú para que los niños puedan obtener las necesidades nutricionales indicadas y así hacer más productivo su desempeño escolar, ya que las necesidades nutricionales diarias de macronutrientes, la cantidad de calorías, fibras y hierro ofrecidas en los menús fueron arriba de la recomendación. Además de priorizar los alimentos regionales en los menús.
\end{abstract}

Palabras clave: Composición nutricional; Menús; PNAE; Alimentación escolar; Escuelas publicas.

\title{
1. Introdução
}

"O período escolar engloba crianças entre 6 a 10 anos de idade, sendo que o crescimento neste período é lento, mas constante, ocorrendo crescente maturação das habilidades motoras e ganho no crescimento cognitivo, social e emocional" (Brasil, 2012).

Além do mais, as crianças em fase escolar já apresentam capacidade de escolhas, gostos próprios e aversões, grandes aliados para a construção alimentar. A publicidade alimentar e as orientações sobre hábitos alimentares contribuem para o desenvolvimento destes hábitos alimentares (Brasil, 2012).

A alimentação escolar é de suma importância para todas as crianças, pois a falta ou excesso podem evitar desatenção durante as aulas, sedentarismo ou baixo rendimento no período escolar. E para que isso ocorra, o Programa Nacional de Alimentação Escolar (PNAE) deve seguir corretamente as próprias diretrizes e recomendações na elaboração de cardápios (Brasil, 2009).

Segundo Tucunduva $(2014$, p.5) "uma alimentação adequada é aquela que atende as necessidades nutricionais do indivíduo." Pela mesma razão, os alimentos de uma dieta devem ofertar energia e nutrientes em quantidades equilibradas e suficientes.

$\mathrm{O}$ ambiente escolar sucede o aumento de ingestões alimentares, período em que as crianças demonstram interesse pelos alimentos e passam a ter necessidades nutricionais mais elevadas (Brasil, 2012).

De certo, as consequências de uma alimentação não saudável no período escolar como baixo peso, retardamento do crescimento e desenvolvimento físico e mental, influencia também na repetência escolar e no desenvolvimento de doenças que poderão comprometer a vida adulta (Brasil, 2006).

Para exemplificar, a ingestão inadequada, doenças nutricionais com anemia, falta de vitamina ou iodo, fatores psicológicos e sociais e o modo de vida ocorrem devido ao aumento de alimentos calóricos ou pela falta de alimentos seguros. Conclui-se que a escola deve produzir e oferecer lanches seguros e de qualidade (Brasil, 2006).

Para assegurar a oferta adequada na alimentação escolar em Manaus, o presente estudo tem como objetivo avaliar os cardápios quanto a composição nutricional das Escolas Municipais, área urbana e rural, da cidade de Manaus com base nos critérios estabelecidos na elaboração de cardápios do Programa Nacional de Alimentação Escolar (PNAE). 


\section{Metodologia}

Segundo Pereira et al. (2018) é uma pesquisa do tipo descritivo, com abordagens qualitativas (Severino, 2014) por meio de avaliações e interpretações dos cardápios em estudo e as abordagens quantitativas focadas na composição nutricional dos mesmos, desenvolvida no município de Manaus-AM, realizado no período de junho de 2020 a julho de 2021.A avaliação dos documentos foi realizada com cardápios de 2019 do Ensino Fundamental I (6 a 10 anos) da área urbana e rural, disponibilizados no site oficial da Secretaria Municipal de Educação (Semed), cidade de Manaus- AM.

A coleta de dados foi realizada por meio da avaliação e análise de cardápios de lanches, área urbana e rural, ano de 2019, para crianças do Ensino Fundamental I com idades de 6 a 10 anos.

Para alcançar os dados que possibilitaram chegar aos objetivos do artigo foram utilizados cardápios retirados do site oficial da Secretaria Municipal de Educação (Semed), junto com levantamento da literatura de Livros, Revistas, Legislações e artigos de sites como SCIELO (Scientific Eletronic Library), PubMed (Serviço da National Library of Medicine), Periódico Capes (Coordenação de Aperfeiçoamento de Pessoal de Nível Superior) e Google Acadêmico.

Os descritores utilizados para buscar artigos nas plataformas mencionadas foram Composição nutricional, Cardápios, Pnae, Alimentação Escolar, Escolas Públicas, Merenda Escolar, Cálcio, Ferro, Alimentação Adequada.

Para análise das informações foram construídos gráficos no programa Microsoft Excel® versão 2013 para avaliar a composição nutricional dos cardápios de lanche/almoço, focado nos macronutrientes (carboidratos, proteína, lipídeos totais) e micronutrientes (cálcio e ferro) oferecidos nas Escolas Municipais conforme os critérios estabelecidos para elaboração de cardápios do programa PNAE.

\section{Resultados e Discussão}

No Estatuto da Criança e do Adolescente (ECA), artigo 2 $2^{\circ}$, são classificadas crianças com idade entre 0 a 12 anos incompletos. Além disso, assegura que toda criança e adolescente deve ter o ensino fundamental como obrigatório e gratuito (Brasil, 1990).

As crianças dos 6 aos 10 anos já apresentam preferências em seu padrão alimentar seja junto com família ou na própria escola, e ter uma alimentação escolar saudável e adequada contribui para a promoção do bem estar, do crescimento, do desenvolvimento de aprendizagem e incentiva na formação de práticas alimentares saudáveis (Brasil, 2012).

Krause (2013) define que "alimentação saudável é aquela na qual se ingerem alimentos de forma equilibrada para que adultos mantenham seu peso ideal e crianças desenvolvam-se adequadamente tanto intelectual quanto fisicamente.”

\section{Programa nacional de alimentação escolar (PNAE) e suas diretrizes.}

O Programa Nacional de Alimentação Escolar - PNAE, desde 1955, popularmente conhecido como merenda escolar, tem como "objetivo promover a formação de práticas alimentares saudáveis e suprir as necessidades nutricionais dos escolares durante sua permanência na escola, contribuindo para o seu desenvolvimento, rendimento escolar, aprendizagem e desenvolvimento biopsicossocial" (Brasil, 2009).

Os cardápios escolares são ofertados sempre com base nas diretrizes da Resolução no 26 de 17 de junho de 2013, Programa Nacional de Alimentação Escolar (PNAE), veja-os a seguir:

“Art. $1^{\circ}$. Para os efeitos desta Lei, entende-se por alimentação escolar todo alimento oferecido no ambiente escolar, independentemente de sua origem, durante o período letivo.

Art. $2^{\circ}$. São diretrizes da alimentação escolar: 
I - o emprego da alimentação saudável e adequada, compreendendo o uso de alimentos variados, seguros, que respeitem a cultura, as tradições e os hábitos alimentares saudáveis, contribuindo para o crescimento e o desenvolvimento dos alunos e para a melhoria do rendimento escolar, em conformidade com a sua faixa etária e seu estado de saúde, inclusive dos que necessitam de atenção específica;

II - a inclusão da educação alimentar e nutricional no processo de ensino e aprendizagem, que perpassa pelo currículo escolar, abordando o tema alimentação e nutrição e o desenvolvimento de práticas saudáveis de vida, na perspectiva da segurança alimentar e nutricional;

III - a universalidade do atendimento aos alunos matriculados na rede pública de educação básica;

IV - a participação da comunidade no controle social, no acompanhamento das ações realizadas pelos Estados, pelo Distrito Federal e pelos Municípios para garantir a oferta da alimentação escolar saudável e adequada;

V - o apoio ao desenvolvimento sustentável, com incentivos para a aquisição de gêneros alimentícios diversificados, produzidos em âmbito local e preferencialmente pela agricultura familiar e pelos empreendedores familiares rurais, priorizando as comunidades tradicionais indígenas e de remanescentes de quilombos;

VI - o direito à alimentação escolar, visando a garantir segurança alimentar e nutricional dos alunos, com acesso de forma igualitária, respeitando as diferenças biológicas entre idades e condições de saúde dos alunos que necessitem de atenção específica e aqueles que se encontram em vulnerabilidade social."

Os cardápios são baseados nas diretrizes como forma de empregar uma alimentação saudável nas escolas, utilizando alimentos mais seguros e regionais, tentando suprir as necessidades nutricionais durante a permanência na escola, consequentemente contribui na promoção de bem estar, desenvolve melhorias e bons resultados na aprendizagem dos estudantes de acordo com suas faixas etárias (Brasil, 2012).

\section{As recomendações do PNAE para elaboração dos cardápios escolares e o papel do nutricionista}

Conforme a Resolução $\mathrm{n}^{\circ} 26$ de 17 de junho de 2013, artigo $14^{\circ}$, ressalta sobre os critérios de elaboração dos cardápios mais significativos para este estudo no que se refere ao PNAE são:

[...]no mínimo 20\% (vinte por cento) das necessidades nutricionais diárias quando ofertada uma refeição, para os demais alunos matriculados na educação básica, em período parcial; A porção ofertada deverá ser diferenciada por faixa etária dos alunos, conforme as necessidades nutricionais estabelecidas; Os cardápios, elaborados a partir de Fichas Técnicas de Preparo, deverão conter informações sobre o tipo de refeição, o nome da preparação, os ingredientes que a compõe e sua consistência, bem como informações nutricionais de energia, macronutrientes, micronutrientes prioritários (vitaminas A e C, magnésio, ferro, zinco e cálcio) e fibras. Os cardápios devem apresentar, ainda, a identificação (nome e CRN) e a assinatura do nutricionista responsável por sua elaboração; Os cardápios deverão oferecer, no mínimo, três porções de frutas e hortaliças por semana (200g/aluno/semana) nas refeições ofertadas, sendo que as bebidas à base de frutas não substituem a obrigatoriedade da oferta de frutas in natura; a oferta de doces e/ou preparações doces fica limitada a duas porções por semana, equivalente a 110 kcal/porção (Resolução no 26 de 17 de junho de 2013, artigo 14º).

As proibições e restrições do PNAE são censuradas em relação a oferta de bebidas com baixo valor nutricional e são restritas nas compras de alimentos prontos e semiprontos como enlatados e embutidos, ou nas guloseimas (Brasil, 2013).

Conforme a Resolução nº65/2010 do Conselho Federal de Nutricionistas (CFN), o cardápio é uma "ferramenta operacional que relaciona os alimentos destinados a suprir as necessidades nutricionais individuais ou coletivas, discriminando os alimentos, por preparação, quantitativo per capita, para energia, carboidratos, proteínas, lipídios, vitaminas e minerais e conforme a norma de rotulagem".

Em síntese, para Guimaraes e Galisa (2008, p.75) cardápio é um guia com preparações alimentares que representa as refeições de um determinado dia ou período. 
Ressalta-se que o cardápio de uma merenda escolar "deve haver um envolvimento de toda a comunidade escolar, alunos, professores, funcionários, pais e nutricionista, que participem de forma integrada em estratégias e programas de promoção da alimentação saudável, garantindo assim a qualidade das refeições servidas” (Brasil, 2012).

Para que o programa tenha êxito, é necessário principalmente a participação árdua do responsável técnico nutricionista, seguindo os critérios da legislação:

Para a efetividade e eficácia do PNAE é importante que todos os sujeitos envolvidos (Entidades Executoras, o Conselho de Alimentação Escolar e o nutricionista responsável técnico) estejam integrados e ativos como responsáveis e co-responsáveis em sua execução, atendendo aos princípios e diretrizes de promover a alimentação escolar saudável e adequada em conformidade com a faixa etária, o sexo, a atividade física e o estado de saúde, incluindo as necessidades alimentares específicas. Isto deve ser feito buscando respeitar a cultura, as tradições e os hábitos alimentares, garantindo assim o controle social, a segurança alimentar e nutricional e o tratamento igualitário dos escolares com necessidades alimentares especiais em função de seu estado de saúde (FNDE, 2012).

Segundo a lei 11.947/2009, os cardápios devem ser compostos por alimentos básicos, respeitando os hábitos alimentares e a cultura alimentar regional, planejados por um nutricionista responsável técnico (Brasil, 2009).

Visto que é fundamental o cardápio valorizar a safra e a cultura alimentar regional tal como proporcionar alimentos contínuos de alto valor nutricional, como frutas e verduras, garantindo melhor aceitação e assim incentivar o consumo destes alimentos importantes. (Brasil, 2012).

$\mathrm{Na}$ alimentação escolar "apesar da legislação do FNDE exigir apenas o mínimo de 3 porções de frutas e verduras por semana, reconhece-se que o ideal seria o consumo diário destes alimentos” (Brasil, 2012).

A lei $n^{\circ} 11.947$, de 16 de junho de 2009 também incentiva compras de gêneros alimentícios regionais quando no mínimo 30\% do total é repassado pelo FNDE para investir em compra direta de produtos da Agricultura Familiar, priorizando as unidades tradicionais indígenas e os quilombolas.

O uso obrigatório dos produtos de agricultura familiar incentiva a aquisição desses produtos valorizando a cultura local, o empreendedorismo familiar rural e assim reduz a situação de pobreza e insegurança alimentar (FNDE, 2017).

Deve-se observar na fase escolar quais as deficiências nutricionais frequentes entre estas crianças e " entre as deficiências, destaca-se a anemia ferropriva (por deficiência de ingestão de ferro) e a hipovitaminose A que podem comprometer o aprendizado do escolar" (Brasil, 2012).

Para entender melhor, Tuncunduva (2014) define "tradicionalmente que as recomendações nutricionais com a quantidade de energia e nutrientes que atende as necessidades da maioria dos indivíduos de um grupo ou uma população".

Enquanto "nutrientes são substâncias que estão presentes nos alimentos e são absorvidas pelo corpo humano para nutri-lo" (Brasil, 2007).

Os benefícios e a divisão desses nutrientes são:

[...]macronutrientes (carboidratos, proteínas e gorduras) e micronutrientes (vitaminas e minerais). Apenas os macronutrientes são responsáveis pelo fornecimento de energia, que às vezes é indicada como "caloria" do alimento [...]. Tanto as vitaminas quanto os minerais, são essenciais na digestão, na circulação sanguínea e no funcionamento intestinal, além de fortalecerem o sistema imunológico, responsável pela defesa do nosso corpo contra invasores como vírus, bactérias e parasitas (Brasil,2009)

É evidente que na idade escolar de 6 a 11 anos é importante consumir alimentos nutritivos, por exemplo, de origem animal ricos em ferro como carnes e vegetais ricos em ferro evitando anemias que não afete o aprendizado para melhor resposta imunológica (Brasil, 2012). 
Além do micronutriente cálcio para desenvolver a massa óssea e muscular e assim reduzir fraturas na vida escolar da criança ou osteoporose na vida adulta, logo é de suma importância não retirar alimentos lácteos dos cardápios (Brasil, 2012).

Com esse intuito, as necessidades nutricionais diárias de uma refeição oferecida, de acordo com as recomendações do PNAE, para a faixa etária entre 6 a 10 de idade são: $300 \mathrm{kcal}$, distribuídas em 9,4g de proteínas, 7,5 de lipídios, 5,4 de fibras e 48,8 de carboidratos (Resolução n³8/2009 do FNDE). No Gráfico 1, os teores médios de energia dos cardápios analisados resultaram em 408,47 Kcal, distribuídos em 17, 07g de proteínas, 10,09g de lipídios, 63,27g de carboidratos e 5,53 g de fibras.

Gráfico 1. - Valores médios de macronutrientes e fibras analisadas nos cardápios de Escolas Municipais da área urbana e rural de Manaus, segundo Resolução do FNDE/PNAE.

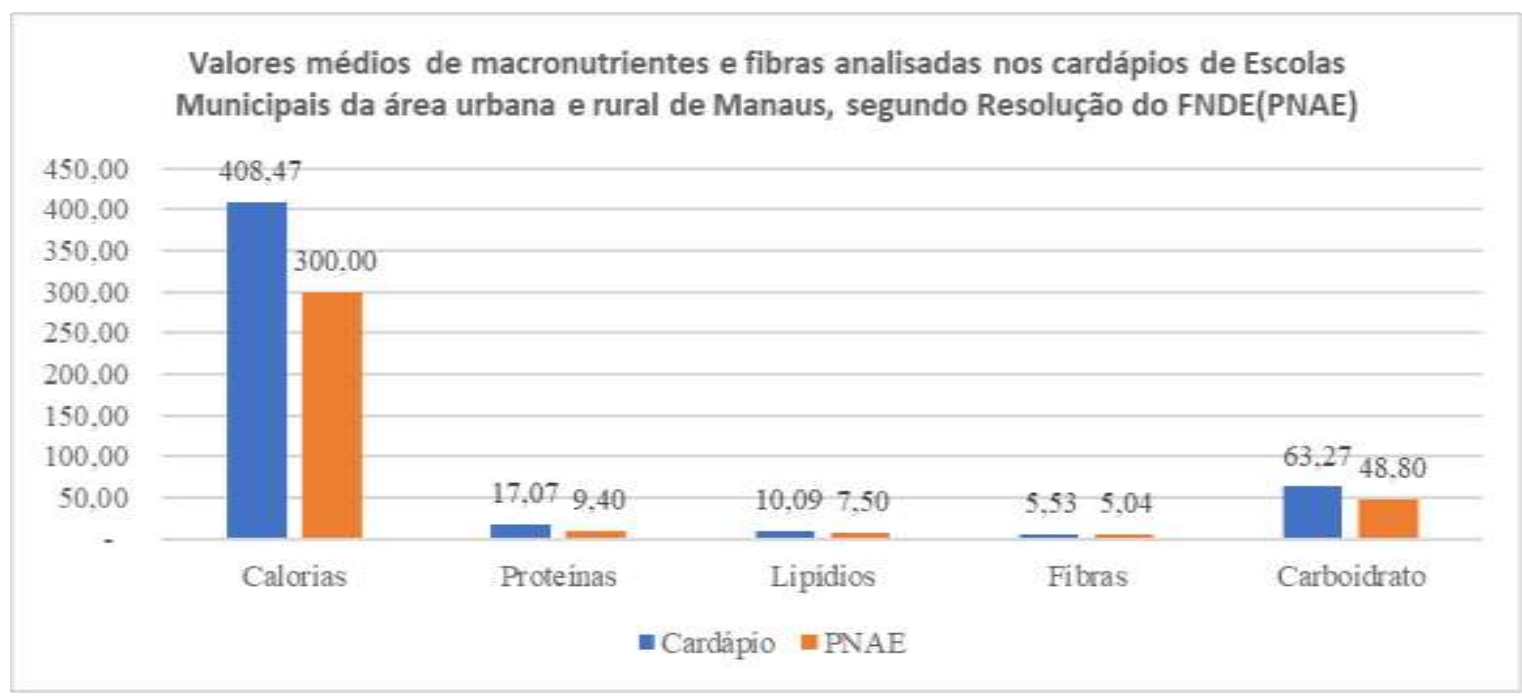

Fonte: Autores (2021).

Pode-se observar que os valores de referência da quantidade de energia, macronutrientes e fibras são preocupantes, pois todos estão acima dos valores de referência recomendado pelo PNAE.

Além do mais, os cardápios avaliados apresentaram ausência e falta de prioridade por alimentos regionais, visto que a Lei $\mathrm{n}^{\circ}$ 11.947, de 16 de junho de 2009 estabelece que "no mínimo 30\% do valor repassado aos Municípios devem ser aproveitados na compra de alimentos vindos da agricultura familiar” como já mencionado.

Gráfico 2. - Valores médios de cálcio e ferro analisadas nos cardápios de Escolas Municipais da área urbana e rural de Manaus, segundo Resolução do FNDE/ PNAE

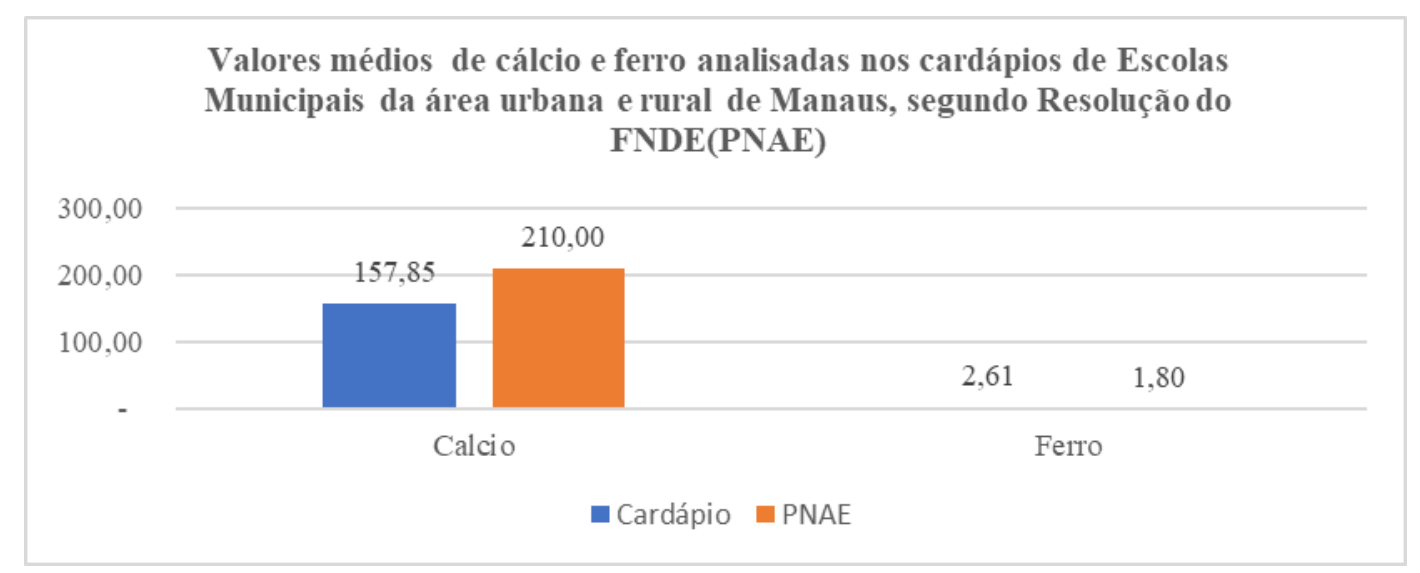

Fonte: Autores (2021). 
O Gráfico 2 apresenta algumas necessidades nutricionais como Cálcio e Ferro oferecidos nos cardápios, segundo as recomendações do Pnae. Logo, a quantidade do cálcio é de 157,85 mg e o ferro é 2,61mg, ou seja, o cálcio está dentro da recomendação enquanto o ferro se encontra acima do valor de referência.

\section{Conclusão}

Com este estudo, conclui-se que é necessário realizar mudanças e equilíbrio no cardápio para que as crianças possam obter as necessidades nutricionais adequadas e assim tornar o rendimento escolar dessas crianças mais produtivo, já que passam mais tempo no ambiente escolar e as necessidades nutricionais diárias de macronutrientes, quantidade de calorias, fibras e ferro oferecidos nos cardápios estavam acima da recomendação do PNAE.

De modo geral, os cardápios avaliados das Escolas Municipais da área urbana e rural para as crianças com idades de 6 a 10 anos estão adequados em relação a oferta de quantidade frutas e saladas por semana.

Por fim, observou-se também que os cardápios avaliados apresentaram ausência e falta de prioridade por alimentos regionais, mostrando dificuldade e deficiência na Lei $\mathrm{n}^{\circ}$ 11.947, de 16 de junho de 2009 que determina no mínimo 30\% do valor repassado pelo Fundo Nacional de Desenvolvimento (FNDE) para compras de gêneros alimentícios direto da agricultura familiar. Sugere-se monitoramento dos conselhos designados para essa função consequentemente resultará melhores rendimentos e desenvolvimento dos alunos, reduzindo riscos de saúde atuais e futuros.

\section{Referências}

Albuquerque, M. de F. M. (2009). A segurança alimentar e nutricional e o uso da abordagem de direitos humanos no desenho das políticas públicas para combater a fome e a pobreza. Revista Nutrição. 22(6), 895-903.

Ane, G. B., et al. (2020). Ações de alimentação e nutrição na atenção primária à saúde no Brasil. Revista Panam Salud Publica. 44.

Bianchini, V. U., et al. (2020). Criteria adopted for school menu planning within the framework of the Brazilian School Feeding Program. Revista de Nutrição. 3, e19019.

Brasil. Constituição Federal. (2009). Capítulo III - Da Educação, da Cultura e do Desporto, Art. 286. http://www.planalto.gov.br/ccivil_03/constituicao/constituicao.htm.

Brasil. Alimentação Escolar. Lei no 11.947, de 16 de junho de 2009. http://www.planalto.gov.br/ccivil_03/_ato2007-2010/2009/lei/111947.htm.

Brasil. Estatuto Da Criança E Do Adolescente. Lei $n^{o}$ 8.069, de 13 de julho de 1990. https://www2.camara.leg.br/legin/fed/lei/1990/lei-8069-13-julho-1990372211-publicacaooriginal-1-pl.html.

Brasil. Ministério De Educação. (2009). Alimentação e Nutrição no Brasil. 92.

Brasil. Ministério De Educação. (2007). Alimentação Saudável e sustentável. http://portal.mec.gov.br/index.php?option=com_docman\&vie $\mathrm{w}=$ download\&alias=611-alimentacao-saudavel $\&$ Itemid=30192.

Brasil. Ministerio De Educação. (1990). Agricultura familiar. http://www.fnde.gov.br/programas/pnae/pnae-eixos-de-atuacao/pnae-agriculturafamiliar\#: :text=A\%20Lei\%20n\%C2\%BA\%2011.947\%2C\%20de\%2016\%20de\%20junho,as\%20comunidades\%20tradicionais\%20ind \%C3\%ADgenas\%20e $\% 20$ as $\% 20$ comunidades $\% 20$ quilombolas.

Brasil. Ministério Da Saúde. Secretaria De Atenção À Saúde. (2013). Política Nacional de Alimentação e Nutrição / Ministério da Saúde, Secretaria de Atenção à Saúde. Departamento de Atenção Básica. Básica. Ministério da Saúde. 84, il.

Brasil. Ministério De Educação. (2018). Manual de apoio para atividades técnicas do nutricionista no âmbito do PNAE / Programa Nacional de Alimentação Escolar: FNDE, 106, il. color.

Brasil. Ministério De Educação. (2012). O Papel do Nutricionista no Programa Nacional de Alimentação Escolar (PNAE) (Manual de instruções operacionais para nutricionistas vinculados ao PNAE). (2a ed.), 40.

Brasil. Ministério De Educação. (2007). Organização e operação de cozinhas escolares. http://portal.mec.gov.br/seb/arquivos/pdf/profunc/14_cozinhas.pdf.

Brasil. Ministério De Educação. Secretaria De Educação Básica. (2006). Políticas de Alimentação Escolar. 88.

Brasil. Ministério De Educação. (2017). RESOLUÇÃO № 26 DE 17 DE JUNHO DE $2013 . \quad$ https://www.fnde.gov.br/acesso-ainformacao/institucional/legislacao/item/4620-resolu\%C3\%A7\%C3\%A3o-cd-fnde-n\%C2\%BA-26,-de-17-de-junho-de-2013. 
Brasil. Ministério De Educação. (2009). RESOLUÇÃO/CD/FNDE N @ 38, DE 16 DE JULHO DE 2009. ttps://www.fnde.gov.br/index.php/acesso-ainformacao/institucional/legislacao/item/3341-resolução-cd-fnde-noo-38-de-16-de-julho-de-2009.

Brasil. Ministério De Educação. Fundo Nacional De Desenvolvimento Da Educação (FNDE). (2012). Manual de orientação para a alimentação escolar na educação infantil, ensino fundamental, ensino médio e na educação de jovens e adultos. 2. ed. Brasília, 48.

BRASIL. PNAE - $\quad$ Programa Nacional De Alimentação Escolar. (2009). $\quad$ Lei $n^{\circ} \quad 11.947 / 2009$. https://www.google.com/search?q=Lei+n\%C2\%BA+11.947\%2F2009\%3A+Define+alimenta\%C3\%A7\%C3\%A3o+escolar+como+todo+alimento+oferecido+ no+ambiente+escolar\%2C+independentemente+de+sua+origem $\% 2 \mathrm{C}+$ durante+o+per\%C3\%ADodo+letivo.\&oq=Lei+n\%C2\%BA+11.947\%2F $2009 \% 3 \mathrm{~A}+\mathrm{Defi}$ ne+alimenta $\% \mathrm{C} 3 \% \mathrm{~A} 7 \% \mathrm{C} 3 \% \mathrm{~A} 3 \mathrm{o}+$ escolar+como+todo+alimento+oferecido+no+ambiente+escolar $\% 2 \mathrm{C}+$ independentemente+de+sua+origem $\% 2 \mathrm{C}+$ durante $+\mathrm{o}$ +per\%C3\%ADodo+letivo.\&aqs=chrome..69i57.1160j0j7\&sourceid=chrome\&ie=UTF-8\#.

Decker, M., Strack, M. H. \& Giovanoni, A. B. (2013). Avaliação da alimentação escolar oferecida aos alunos do Ensino Fundamental das Escolas Municipais em um Município do Vale do Taquari - RS. Rev. Destaque Acadêmicos. 5(3), 13-18.

Dias, L. C. D., Cintra, R. M. G. De C., Souza. J. T. \& Aranha, C. G. S. (2012). Valor nutricional da alimentação escolar oferecida em uma rede municipal de ensino. Revista Ciência em Extensão. 8(2), 134-143.

Doratioto, R. A. \& Buongermino, S. S. (2001). Ingestão de energia e nutrientes por adolescentes de uma escola pública. Jornal de Pediatria, 77(6).

Elisabeth, M., Hiromi, G. \& Carolina, M. (2015). Técnica dietética aplicada à dietoterápica. Manole, 180.

Galisa, M., Nunes, A., Garcia, L. \& Chemin, Sandra. (2014). Educação Alimentar e Nutricional da teoria à prática. Roca.

Fernandes, F. M. (2006). Alimentação e nutrição entre escolares: caso dos alunos de uma escola do município. 49 f. Monografia (Especialização em Nutrição Clínica). Universidade Veiga de Almeida, Vitória.

Francieli, L.C. (2014). A importância de uma alimentação adequada na educação infantil. 32f. Monografia de especialização. Universidade Tecnológica Federal do Paraná. Ibaiti, Paraná.

FNDE- Manual de orientação para a alimentação escolar na educação infantil, ensino fundamental, ensino médio e na educação de jovens e adultos. (2012). (2a ed.), PNAE: CECANE-SC.

FNDE. Caderno de Referência: Alimentação Escolar para Estudantes com Necessidades Alimentares Especiais. 2017. 66.

FNDE- Programa Nacional de Alimentação Escolar - PNAE. Referências Nutricionais para o Programa Nacional de Alimentação Escolar. 2009.

Franco, Cristiane de Oliveira et al. (2014). Avaliação do consumo de cálcio por adolescentes. Revista Paul Pediatra. 32(2), 216-20.

Goldschmidt, P. S. \& Granada, G. G. (2008). Biodisponibilidade de ferro na merenda escolar. Alimentação Nutricional Araraquara, 19(4), 441-448.

Gomes, C. E. \& Fanhani, A.P. (2014). Avaliação da qualidade nutritiva do cardápio da alimentação escolar de Luiziana, PR, Brasil. Rev. Saúde e Biol. 9(3), 54-61.

Galisa, M. \& Guimaraes, A. (2008). Cálculos Nutricionais: Conceitos e Aplicações Práticas. M. Books.

Histórico. - SOBRE PNAE. https://www.fnde.gov.br/index.php/programas/pnae/pnae-sobre-o-programa/pnae-historico.

Karollyne, A. Q. (2015). Análise dos cardápios de pré-escolares de escolas municipais de Assú-RN. Revista Cientifica da Escola da Saúde. 4(3), 63-72.

Leão, P. V., et al. (2019). Análise dos cardápios elaborados em um município do nordeste paraense. Cadernos Saúde Coletiva, $27(3), 264$ - 271.

Lemke. S. Programa Nacional De Alimentação Escolar- Cardápios na Alimentação Escolar. Ministerio da Saúde. Coordenação de Segurança Alimentar e Nutricional - COSAN.

Mahan, Kathleen L. (2013). - ESCOTT-STUMP, Sylvia - RAYMOND, Janice L. Krause Alimentos, Nutrição e Dietoterapia. $13^{\circ}$ ed. Rio de Janeiro: Elsevier. 1228.

Marcondes, I., de O. (2019). Avaliação qualitativa das preparações do Cardápio de Escolas Estaduais. 50f.

Maria, A. L. P. (2013). A trajetória do Programa Nacional de Alimentação Escolar no período de 2003-2010: relato do gestor nacional. Ciência \& Saúde Coletiva. 18(4), 909-916.

Maria, V. de S. B., et al. Estado nutricional e avaliação qualitativa do cardápio de escolas de educação infantil.

Marreira, G. V., Boro, M. V. \& Sousa, A. A. (2015). Cardápios escolares em Santa Catarina: avaliação perante a regulamentação do Programa Nacional de Alimentação Escolar. Revista de Nutrição. 28(3), 277-287.

Muniz, V. M., Carvalho, A.T. (2007). O Programa Nacional de Alimentação Escolar em município do estado da Paraíba: um estudo sob o olhar dos beneficiários do Programa. Revista de Nutrição. 20(3), 285-296.

Paiva, N. de F. X. (2016). Cardápio e qualidade: composição nutricional na alimentação escolar. 2019. 71F. Dissertação (Mestrado em Gestão de Programas e Serviços de Saúde) - Universidade Ceuma.

Pereira, A. S., Shitsuka, Dorlivete M., Parreira, Fabio José \& Shitsuka, Ricardo. (2018). Metodologia da Pesquisa Cientifica. 1.ed., Santa Maria, RS: UFSM, NTE. 
Research, Society and Development, v. 10, n. 7, e25810716687, 2021

(CC BY 4.0) | ISSN 2525-3409 | DOI: http://dx.doi.org/10.33448/rsd-v10i7.16687

PNAE- Programa Nacional De Merenda Escolar. (2017). Pesquisa sobre Pnae. https://www.fnde.gov.br/index.php/programas/pnae/pnae-sobre-oprograma/pnae-sobre-o-pnae.

Porrua, P. et al. (2020). Avaliação da Gestão do Programa Nacional de Alimentação Escolar sob a ótica do fomento da agricultura familiar. Caderno Saúde Coletiva. 28(3), 426-437.

Rosane, C. P. A. T. (2017). Direito humano à alimentação adequada: percepções e práticas de nutricionistas a partir do ambiente escolar. Trab. Educ. Saúde. $15(1), 245-267$

SEMED- Secretaria Municipal de Educação. Pesquisa de Cardápios de 2019. https://semed.manaus.am.gov.br/escolas-urbanas-e-rodoviarias-2019/.

Severino, A. J. (2013). Metodologia do Trabalho Cientifico. Cortez.

Silva, A. C. et al. (2016). Avaliação da composição nutricional dos cardápios da alimentação escolar das escolas da rede municipal de tempo integral do Município de Fortaleza, CE. Revista Digital. 20, 212.

Sousa, A. A., et al. (2015). Cardápios e sustentabilidade: ensaio sobre as diretrizes do Programa Nacional de Alimentação Escolar. Revista de Nutrição, 28(2), 217-229.

Tuncuduva, S. (2014). Pirâmide de Alimentos: fundamentos básicos da nutrição. 2 ed. rev. Barueri: Manole, 2014. 399.

Valente, Paula Leão et al. (2019). Análise dos cardápios elaborados em um município do nordeste paraense. Caderno Saúde Coletiva. $27(3), 264-271$.

Xerez, N. de P. F. (2016). Cardápio e qualidade: composição nutricional na alimentação escolar.71f. Dissertação (Mestrado em Gestão de Programas e Serviços de Saúde) - Universidade Ceuma, São Luís. 